\title{
LITERATURWISSENSCHAFT
}

BEATE SOMMERFELD

\section{„Es ist für Augenblicke, als würde die Schale der Erde unter einem zu Kristall..." - ,Plötzlichkeit‘ als Konturierung des Augenblicks in Hugo von Hofmannsthals Aufzeichnungen und Tagebüchern}

W zapiskach i dziennikach Hofmannsthal prowadzi intensywny spór z pojęciem chwili, z którym spotykał się między innymi w dziennikach francuskiego diarysty Amiela. Ulotność i nieuchwytność chwili wiąże się dla Hofmannsthala z problemem jej przedstawialności artystycznej. Takiemu postrzeganiu chwili w zapiskach i dziennikach przeciwstawia próby jej uchwycenia. Zawarte w nich refleksje o wyodrębnionej z czasowego kontinuum i noszącej znamiona epifaniczności chwili, w której poprzez nawiązanie kontaktu ze światem zewnętrznym zjawia się życie jako całość, korespondują z przemyśleniami autora z tekstów fikcjonalnych. W zapiskach i dziennikach Hofmannsthal zawiera przede wszystkim refleksje o charakterze aforystycznym, których przedmiotem jest owa szczególna, scalająca życie chwila. W dziennikach spotkać można relacje z przeżywanych epifanii, wokół których zbudowana jest narracja. Są one punktem wyjścia literackiego przedstawienia w myśli Nietzschego emfatycznie postrzeganego życia, do którego docierać można jedynie chwilami. W owych momentach podmiot odzyskuje swoją tożsamość zatracając się. Na tle tych rozważań przy analizie zapisków i dzienników Hofmannsthala uzasadnione wydaje się posłużenie się terminologią Karla Heinza Bohrera. Postrzeganie chwili w myśl terminu ,nagłości ‘ Bohrera dla pisarstwa Hofmannsthala wydaje się szczególnie produktywne. Literackie przedstawienie owego doświadczenia ,nagłości ‘ niemieszczącego się w tradycyjnej poetyce stanowi - jak Bohrer ukazał na przykładzie opowiadań Hofmannsthala - wyzwanie dla autora. Także w wierszach takich jak ,Przeżycie“ autor skupia się na przedstawieniu nagłego lęku wywoływanego poczuciem zagubienia wobec całości życia, której podmiot liryczny nie może ogarnać. Chwila jako spojrzenie (Augen-Blick) na przedmioty ze świata zewnętrznego - a także na siebie samego - stanowi o lęku podmiotu oddalonego od życia, który ,życie‘ 
Beate Sommerfeld

doświadczyć może jedynie jako brak kontynuum i na pograniczu językowej przedstawialności.

Hugo von Hofmannsthal führt in den Aufzeichnungen eine intensive Auseinandersetzung mit dem Augenblick des Ästhetizismus, dessen Formlosigkeit als künstlerisches Gestaltungsproblem begriffen wird. Er versucht, dem ungreifbar vorüberziehenden Zeitpunkt auf mehrerlei Art und Weise eine prägnantere Augenblicksvorstellung entgegenzusetzen. Die in Aufzeichnungen und Tagebüchern formulierten Reflexionen über die aus dem zeitlichen Kontinuum herausgehobenen Momente mit epiphaner Struktur, in denen der Kontakt mit den Dingen der Außenwelt die Ganzheit des Lebens aufschimmern lässt, korrespondieren mit den in Ein Brief oder dem Gespräch über Gedichte dargelegten Überlegungen. In Hofmannsthals Aufzeichnungen und Tagebüchern erscheint der Augenblick vorwiegend als aphoristisch zugespitzte Reflexion. In den Tagebüchern werden in einigen Eintragungen Augenblicke mit epiphanem Charakter als erlebt geschildert, wobei der Augenblick zum Element narrativer Strukturierung wird. Sie sind der Ausgangspunkt einer literarischen Gestaltung des im Sinne Nietzsches emphatisch verstandenen, nur in Augenblicken erfahrbaren ,Lebens', in denen das Subjekt seine Identität auf dem Wege der Entgrenzung wiedergewinnt. Insofern scheint es sinnvoll, sich bei der Analyse der Hofmannsthalschen Tagebücher innerhalb der Terminologie Karl Heinz Bohrers zu bewegen. Der Augenblick als Moment plötzlichen Erschreckens scheint für Hofmannsthals Schreibpraxis besonders produktiv zu sein. Gerade dieses reine, die Gattungsgrenzen aufsprengende und literarisch schwer zu vermittelnde Erlebnis stellt für den Autor eine Herausforderung dar, wie Bohrer bereits für die Erzählungen Hofmannsthals nachgewiesen hat. Auch in Gedichten wie Erlebnis steht die literarische Gestaltung des Schreckens über die eigene Haltlosigkeit angesichts einer nicht mehr zu erfassenden Lebenskontinuität im Vordergrund. Der Augenblick als Blick auf die Dinge der Außenwelt - auch der Blick auf sich selbst von außen - vermittelt den Schrecken des vom ,Leben“ abgetrennten, außerhalb Stehenden, der ,Leben“ nur noch als Abwesenheit von Kontinuität und an den äußersten Grenzen sprachlicher Vermittlung erfahren kann.

The diaries and notes kept by Hugo von Hofmannsthal illustrate the writer's preoccupation with the problem of the aesthetics of the moment. The shapelessness and fluidity of the moment is perceived as a problem of its literary forgeability. The writer puts forward his own, more palpable conception of the moment, reflecting on inevitably disrupted moments in which experience or vision is concentrated or crystallized. His reflections on this issue in the diaries and notes correspond to the term of ,epiphany' developed in his fictional works such as The Letter of Lord Chandos or Conversation on Poetry. In the notes and diaries the moment is the topic of concise statements which can be characterized as aphorisms. However, there are some notes in which such ,epiphanies' are related as taken from the personal experience of the writer. In these episodes the particular moment is the initial element of the narrative structure. Hofmannsthal thus probes the problem of the continuity of the self and the fluidity of sense experience. His obsession with the fortuitousness and discontinuity of the self can be ascribed to his reading of Nietzsche, due to whom the self must regain its identity by destroying the ,principle of individuation'. His attempts to shape 
the fluid moments in one's life must thus be considered as a reforgeing of identity in terms of modernity. Taking into consideration the obvious influence by Nietzsche's philosophy, it seems valid to make use of the terminology developed by Karl Heinz Bohrer, analyzing Hofmannsthal's diaries and notes. The pure experience of frightening ,suddenness' appears to be of a particular importance for Hofmannsthal's writing. Putting forward the example of Hofmannsthal's stories, Bohrer shows how the ,suddenness ' of the moment challenges literary forms and genres. Also, in the lyrical texts the ,shock' caused by the experience of discontinuity of life occurs in disruptiveness from any past nor any future. The moment - hardly expressable by means of language - as the gruesome experience of pain caused by the consciousness of being apart from life can be regarded as a key modality of aesthetic experience in Hofmannsthal's notes and diaries.

Bis heute wird das Schriftstellertagebuch als Reflexionsraum für die Augenblicksproblematik wahrgenommen. So schreibt BOTHO STRAUSS (1989:194) über die Tagebücher Amiels: „Tag für Tag verhindert er (der Tagebuchschreiber) seine Lebensgeschichte, indem er sie dem prompten Augenblick der nackten Gegenwärtigkeit preisgibt, so daß ein schonendes Imperfekt und die natürliche Selektion der Erinnerung keine Chance haben." Die Schriftstellerin UNDINE GRUENTER (1995:34) reflektiert in ihrem als Arbeitsjournal betitelten Tagebuch folgendermaßen über die Bedeutung des Augenblicks:

Wie nun jenen zerschlagenen Rest, jene Reduktion auf den Kern des Augenblicks selbst beschreiben, der dem heutigen Subjekt allein übrig blieb? Erinnerung und Entwurf als utopisches Denken sind zertrümmert, der Augenblick als Bewußtseinsereignis abgeschnitten, isoliert von ähnlichen in Vergangenheit und Zukunft, verkörpert nur sich selbst, ohne Verbindung auf dem Zeitstrang, kommt aus dem Nichts, fällt ins Nichts - und ist doch in dieser nur noch auf sich selbst verweisenden Form als der Zustand der höchsten das einzige kostbare Zeichen vom geretteten Rest der Subjektivität.

Im Tagebuch ist der Schreiber auf den Augenblick zurückgeworfen, Augenblick und Lebenskontinuum werden gegeneinander ausgespielt. Dabei scheinen sich die Reflexionen über den Augenblick in einer Ambivalenz zwischen Bedrohung und Bewahrung des Subjekts zu bewegen.

In der Moderne als einer Zeit der Infragestellung und gleichzeitig äußerster Bemühungen um die Rettung der Subjektivität erweist sich die Augenblicksthematik als besonders brisant. Im Folgenden sollen Hofmannsthals Werke im Kontext der Augenblicksproblematik um die Jahrhundertwende platziert werden, um dann der Thematik des Augenblicks in Hofmannsthals Aufzeichnungen und Tagebüchern nachzugehen. Dabei steht die Frage im Vordergrund, ob der Schreiber hier vor allem auf den Augenblick reflektiert 
Beate Sommerfeld

oder in Ansätzen auch den Rahmen zu seiner narrativen Vermittlung absteckt.

\section{Die Literatur der Jahrhundertwende zwischen Zeitpunkt und Augenblick}

$\mathrm{Zu}$ Beginn des 20. Jhd.s hat der Zeitbegriff seinen objektiven Charakter eingebüßt. ${ }^{1}$ Die Literatur greift sehr schnell das veränderte Paradigma des Zeitdenkens der Moderne auf. Gerade in der Zeiterfahrung sowie der literarischen Gestaltung der Zeit entwickeln die Autoren der klassischen Moderne in Anlehnung an philosophische Positionen (Nietzsche, Bergson, Kierkegaard) neue Erzählweisen, die quer zur üblichen Zeit des narrativ dargestellten Aufeinanderfolgens verlaufen, und begeben sich so auf die Suche nach einer anderen Zeiterfahrung. Das Kontinuum der Zeit wird pluralisiert oder durch nachdrücklichen Verzicht auf Chronologie oder Lücken in der Darstellung aufgehoben, das teleologische Denken in Entwicklungen durch Augenblicksemphase ersetzt. ${ }^{2}$ Das Problem des Augenblicks wird zum Brennpunkt einer Fülle von kulturellen und lebensweltlichen Phänomenen der Jahrhundertwende. Es erscheint zugleich als Zentrum philosophischer, psychologischer und auch literaturtheoretischer Reflexion. ${ }^{3}$ Die Untersuchungen sind zu einem Großteil in gattungspoetische Überlegungen aufgegliedert, beispielsweise wurde die Funktion des Augenblicks in der Kurzgeschichte (DURZAK 1984) oder der Lyrik (SCHNEIDER 1984) einer Analyse unterzogen. MARKUS FISCHER (1986) sieht eine Korrelation zwischen der um die Jahrhundertwende dominierenden Kurzprosa und dem Bestreben der literarischen Erfassung des Augenblicks. Um einen Zugewinn an Erfahrung zu erzielen, werden in der Moderne Augenblicke aus dem zeitlichen Kontinuum ausgegliedert und Möglichkeiten ihrer narrativen Vermittlung entwickelt, wobei die Tradition der Epiphanie wiederbelebt und modifiziert wird. Aus den Strategien der Bedeutungsaufladung des Augenblicks ergibt sich eine verwirrende Begriffs-

1 Zu einem Überblick über die einschlägige Literatur vgl. РОснат (1984:22); vgl. ebenfalls SIMONIS / SIMONIS (2000:8-18).

2 Zu einer Typologie dieser Strategien vgl. MÜLLER (1997:552-567).

3 FisCHER (1986) geht den Einflüssen Freuds, Breuers und Nietzsche nach. ANNA CZAJKA (2006) untersucht die Wirkung von Blochs Augenblicksverständnis u.a. vor dem Hintergrund Hofmannsthals. 
vielfalt, weshalb es angeraten erscheint, sich auf die Ursprünge des Terminus zu besinnen.

Als zentraler Begriff der Religionsgeschichte markiert die Epiphanie den Einbruch des Göttlichen in die Welt des Menschen (PAX 1955:136). ${ }^{4}$ Etymologisch lässt sich der Begriff vom altgriechischen ,epiphaneia' herleiten, der das Erscheinen eines Gottes bezeichnet, und steht immer im Zusammenhang mit Offenbarung sowie Teilhabe an göttlicher Weisheit. Gegenüber den Epiphanien heidnischer Provenienz kristallisiert sich mit der Zeit der biblische Epiphanie-Begriff als eigene Größe heraus. In theologischer Hinsicht erhält Epiphanie folgende Attribute zugeschrieben: Sie bezeichnet

den Einbruch Gottes in die Welt, der vor den Augen der Menschen unter gestalteten oder ungestalteten Ausdrucksformen, die natürlichen oder geheimnisvollen Charakter tragen, plötzlich erfolgt und ebenso rasch wieder verschwindet. Wesentlich ist die Kürze der Erscheinung, wobei Anfang und Ende hervorragen. (PAX 1962:288f)

Neben der Plötzlichkeit gehört auch die Unwiederholbarkeit zu den Merkmalen der Epiphanie (PAX 1962:290), wobei beides im Erlebenden starke körperliche Reaktionen hervorruft und Furcht und Schrecken mit dem Gefühl der Überwältigung abwechseln. Vom Erlebenden verlangt die als Anruf Gottes intendierte Epiphanie Bekenntnis und Entscheidung (PAX 1962:292) und markiert insofern stets einen lebensgeschichtlichen Einschnitt (PAX 1962: 289f). ${ }^{5}$ Bereits in der Antike lässt sich eine Trennung zwischen der religiöstheologischen und der profanen Bedeutung von Epiphanie beobachten. ${ }^{6}$ Die Verlagerung des Begriffs auf eine ästhetische Ebene führte zu einer Entleerung ihres ursprünglichen Sinngehalts (PAX 1955:46), wobei bestimmte strukturelle Merkmale nachwirken und immer wieder aktualisiert werden. ${ }^{7}$ Die Epiphanie, mythisch-religiösen Ursprungs (HACK 1999:277-280), wurde

$4 \quad$ Zur antiken Begriffsgeschichte vgl. ebenfalls ZAISER (1995:14).

5 Diesen Aspekt betont IRMGARD SCHAROLD (2000:25f.)

6 Epiphanie wurde als dramaturgisches Stilmittel zur Strukturierung unterschiedlicher kultischer Handlungen mechanisiert, womit eine Verflachung der Bedeutung einherging. Diese funktionalistische Inflationierung widerspricht dem auf Einmaligkeit angelegten Wesen der Epiphanie, die nach und nach ihres sakralen Inhalts beraubt wurde. (PAX 1955:48-64)

7 ZAISER (1995:56) optiert daher für eine rein strukturelle Beschreibung der Epiphanien und nennt als wichtigstes Wesensmerkmal die ,Offenbarung‘. 
in die Neuzeit herübergerettet durch die Ästhetisierung des Augenblicks. ${ }^{8}$ In der Moderne bezeichnet die Epiphanie ganzheitliche, das Ich entgrenzende Erlebnisse, als Augenblicks-Ekstasen gestaltet - gesteigerte Wahrnehmungsfähigkeit und intensives Identitätsbewusstsein, emphatisch beschworen als zeitliche Keimzelle äußerster Möglichkeiten der Inspiration, des Einheitsund Identitätsgefühls (GOTTWALD 2003:314). Um dieses nicht länger religiös gebundene Phänomen gegen vertraute, sprachlich zu determinierende Erscheinungen abzugrenzen, wird es häufig auch unter den Begriff des ganz Anderen gefasst, womit eine „substantiell leere Größe bezeichnet ist, in der aber die Möglichkeit von Lebenszusammenhang antizipiert ist" (BARTMANN 1984:193) ${ }^{9}$ - oder aber ganz bewusst auf Sinnstiftung verzichtet wird. Epiphanien beinhalten somit zum einen das Merkmal der Plötzlichkeit, des Aufbrechens von Kontinuität, zum andern das Aufscheinen der Ganzheit des Lebens und somit der Selbstbewahrung des Subjekts.

Im Kontext der modernen Literatur wird Epiphanie innerhalb literaturwissenschaftlicher Terminologie zur Bezeichnung der Konzepte unterschiedlichster Autoren herangezogen, die eine nahezu identische Binnenstrukturierung eines sprachlich kaum erfassbaren Ereignisses gemeinsam haben, wobei Plötzlichkeit und Erleuchtung miteinander korreliert werden (GILLESPIE 1986:258). Epiphanie erscheint in einer schier unerschöpflichen terminologischen Vielfalt, die die Disparität des Begriffs erahnen lassen ${ }^{10}$ : Verwendet werden Bezeichnungen wie ,epiphanies', ,moments of being', ,privileged moments', ,moments of vision“ (ERZGRÄBER 1984:361-387), ,Stunde der wahren Empfindung', ,der andere Zustand', ,die andere Zeit', ,l'autre côté u.v. m. ${ }^{11}$ PAUl Ricoeur $(1989: 212,245)$ vermeidet den Begriff der Epipha-

$8 \quad$ Kulturelle Kontexte moderner Sehnsüchte nach dem Augenblick beleuchtet HELGA NOWOTNY (1993:135-150).

9 BARTMANN (1984:198-200) zieht Verbindungslinien zwischen Musils ,anderem Zustand“ und Handkes ,,anderer Zeit“ und fragt, ,ob Plötzlichkeit und Epiphanie Motivformen sind, die Traditionslinien zwischen Autoren zu ziehen erlauben".

10 Roger WiLlemsen (1984:277f.) sieht den Begriff ,Epiphanie‘ als terminologisch nicht exakt genug definiert, um ihn auf die bei Musil beschriebenen Einheitszustände zu beziehen. Andererseits konstatiert er jedoch die „Evidenz des Zusammenhangs zwischen Epiphanie und dem bei Musil als , anderer Zustand" bezeichneten Phänomen."

11 Zu einem Versuch der Auflistung vgl. HöLLERER (1961:135f.). Auszüge von Beschreibungsversuchen, die Höllerer unter die Erscheinung der Epiphanie fasst: „Brennpunkte“, „Widerspiele“, „Grundfiguren“, das „,phantastische Durchdringen des Subtilen und des Banalen“, „Metamorphosen“, „Momentbilder des Leben- 
nie und verweist auf die von Thomas Mann, Virginia Woolf und Marcel Proust evozierten erhabenen Augenblicke, in denen eine extreme Konzentration der Zeitlichkeit zu Grenzerfahrungen führt, die er als solche der Ewigkeit begriffen wissen will. Das Phänomen des Ausgreifens in transzendente Erfahrungen scheint als Reaktion der anbrechenden Moderne auf Sinndefizite erklärbar zu sein, die von den Autoren mit einem meist nicht-religiösen Sinnangebot ausgefüllt werden. Der Augenblick

[...] fängt, gleichsam für die Länge eines Augenaufschlags, die Ewigkeit noch einmal ein. Mehr und mehr wird das Erlebnis der erfüllten Augenblicke eine sehr subjektive Erfahrung. In der Fülle des Augenblicks sollte sich verdichten, was zunehmend sich entzog: der Sinn. Seit die Ewigkeit als Garant der Sinnsetzung ausfiel, war die Zeit des einzelnen gefordert. (HILLEBRAND 1999:63)

Der emphatische Augenblick gehört somit in einen poetischen Diskurs, der noch im 20. Jhd. die Möglichkeit der transzendenten Erfahrung von Wahrheit in Erwägung zieht. Ihr besonderes Merkmal scheint die Diskontinuität des Zeiterlebens zu sein, das momentane Aufscheinen einer plötzlichen Erfahrung, deren literarische Darstellung THEODORE ZIOLKOWSKI (1961) und KARL HEINZ BOHRER $(1981 ; 2003)$ als Epochensignatur der Moderne analysiert haben. Mit der Etablierung des Phänomens Epiphanie als Zentralbegriff moderner Ästhetik erfolgt der Versuch, diese einem geistesgeschichtlichen Kontinuum zuzuordnen. Die Epiphanie-Diskussion gerät ins Spannungsfeld der für die Moderne so relevanten Zeitproblematik, neben Proust und Bergson wird auch Nietzsche als Bezugspunkt herangezogen. Hofmannsthals Bewusstseinskrise ist das erste ,poetologische Problemereignis in einer langen Kette weiterer Krisen, die durch das Erkennen des ,Augenblicks' hervorgerufen wurden“ (BOHRER 1981:58). Die Isolierung und Hypostasierung des Augenblicks muss vor dem Hintergrund der Subjekt-, Erkenntnis- und Sprachkrise der Jahrhundertwende betrachtet werden (BOHRER 1981:5562). ${ }^{12}$ Die Sprachkrise der Moderne steht im Zusammenhang mit einer Sinnkrise, die aus der Entfremdung von Ich und Welt resultiert - ZIOLKOWSKI (1961:594) wagt den Befund: „Der Dichter ahnt die Existenz einer wahren Welt, aber seine Versuche, sie darzustellen, scheitern an den schlüpfrigen, abgegriffenen Worten, die zu seiner Verfügung stehen.“ ARTUR SCHOPEN-

digen“, „Ambivalenzen“, „Transitions“, „Ineinsbildung von Aktuellstem und mythisch Entrücktem“, „Zusammenschluss von Stasis und Movens“, „Reitersprung zwischen Entgegengesetztem“.

12 Zum Zusammenhang von Sprachkritik und ästhetischer Existenz bei den Autoren der Wiener Moderne vgl. MAGRIS / REINIGER (1982:224-246). 
HAUER (1947:539) schreibt: „Das eigentliche Leben eines Gedankens dauert nur bis er an den Gränzpunkt der Worte angelangt ist ... “ und bringt damit bereits dieses Weltgefühl der Moderne zum Ausdruck, das sich emblematisch in Hofmannsthals Chandos-Brief von 1902 verdichtet. Auch die Briefe eines Zurückgekehrten (1907) thematisieren den Verlust des unmittelbaren Weltkontakts - von Hofmannsthal als „Prä-Existenz“ bezeichnet (ZIOLKOWSKI 1961:598). In dieser Disoziierung von Ich und Welt scheint ein ursprünglicher Weltkontakt auf, dessen Restituierung als zentrales Anliegen der Moderne bezeichnet worden ist: „Der größere Zusammenhang des Bewusstseins verfiel als sprachlicher Zusammenhang, er wurde das Unsagbare. Nur noch einzelne Augenblicke konnten die Illusion nähren, ihre sprachliche Erfassung sei adäquat.“(BOHRER 1981:55) Im Augenblickskult der beginnenden Moderne, die mit Hofmannsthals Chandos-Brief einen ihrer ersten Schlüsseltexte erhielt, sieht BOHRER (1981:63) einen Beleg für ein negatives, ideologiefreies Ausgesetztsein des reflektierenden, aber von tradierten Sicherheiten abgesprengten modernen Künstlers:

Die ,Epiphanie‘ des Augenblicks ist ihm das einzig substantiell Gebliebene. Es ist nicht , symbolisch' interpretierbar, weist nicht über sich hinaus, sondern stellt umgekehrt jede Art von vorweggenommener Kontinuität in Frage. Diese Verabsolutierung des ,Jetzt' zum erscheinenden ,Augenblick', zur poetologischen Struktur der ,Epiphanie“ ist durchgängig zu beobachten als ein Kennzeichen der modernen Literatur. ${ }^{13}$

Einzig der gesteigerte Augenblick, der das Ich in den Zustand emphatischer Wahrnehmung versetzt, vermag dem transzendenzlosen modernen Individuum zumindest ansatzweise Authentizität zu suggerieren. Mit der Vorliebe für Epiphanie und Augenblicke als Modi erzählerischen Gestaltens korrespondiert Bohrer zufolge der damit zusammenhängende Moment der Plötzlichkeit, ein temporaler Index für panische Erwartung, die das Zeitkontinuum schockhaft aufsprengt, das aber auch Glücksmomente bezeichnet, somit als Zeitmaß der momentanen Umstürze des Helden anzusehen ist (GOTTWALD 2003:314-316). Bohrer stellt das um die Jahrhundertwende auftauchende Phänomen der Plötzlichkeits- und Augenblickskultivierung in den geistesgeschichtlichen Kontext der Philosophie Nietzsches, die in einer dionysischen Ablösung vom Denken des Positivismus als radikale Absage an alles Gewohnte und Vertraute einen grundsätzlichen Zweifel am Kausalitäts-

13 ZAISER (1995:53-55) warnt vor einer voreiligen Bindung des Epiphanie-Begriffs an die Vorstellung vom Augenblick, die zu schwach sei, um als Beschreibungsmodell einer literarischen Epiphanie zu dienen. 
prinzip formulierte, tradierten Erkenntnis-Begriffen und Erklärungsmustern misstraute. Der vehemente Einfluss Nietzsches auf die Künstler und Autoren der Jahrhundertwende schafft eine geistesgeschichtliche Konstellation, die auch die Generation des gefährlichen Augenblicks prägte (BOHRER 1981:45). ${ }^{14}$ Die Radikalität und Explosivität von Nietzsches Denken führte zu einer neuen Wahrnehmungs-Angst (BOHRER 1981:46). Diese Augenblickskonzeption verbindet BOHRER (1981:50) mit einer weiteren Quelle, und zwar mit Kierkegaards Dämonisierung des Plötzlichen in Die Krankheit zum Tode aus dem Jahre 1844. Dort bringt Kierkegaard das als das Plötzliche definierte Dämonische mit der Negation der Kontinuität, der Unfähigkeit zur Kommunikation sowie radikalem Solipsismus in Zusammenhang. In der Emanzipation vom theologischen Gehalt gewinnt das Plötzliche eine ästhetische Qualität, die nach Bohrer ihren ersten Niederschlag in der Kultivierung des ,choc'-Begriffs durch Charles Baudelaire gefunden hat. Seither - so BOHRER (1981:47) - kulminierten Plötzlichkeit und Schrecken im dämonischen Augenblick. Bohrers Plötzlichkeit ist eine typisch moderne, avantgardistischer Tradition verpflichtete literarische Verfahrensweise. Auf der anderen Seite ist der Konnex von Epiphanie und Schrecken - wie gezeigt kein rein modernes Phänomen, sondern genuiner Bestandteil der göttlichen Erscheinung selbst. ${ }^{15}$

Was bleibt, ist „die Betroffenheit durch die ,,in Erscheinung“ tretenden Figuren bzw. Phänomene“ (BOHRER 1981:65). So beschreibe Hofmannsthal im

14 Neuere Arbeiten wie diejenige von HeIKE GRUNDMANN (2003:8f.) heben ebenfalls den Einfluss Nietzsches auf Hofmannsthal hervor, setzen jedoch die Schwerpunkte anders: Gerade aus Nietzsches Menschliches, Allzumenschliches habe Hofmannsthal den Gedanken des Fortlebens der Vergangenheit in der Gegenwart bezogen. Mit der Vergangenheit gelte es eine hermeneutische Verschmelzung einzugehen, um zu einem vollen Gegenwartsgefühl zu gelangen. Die Autorin bezieht sich in ihren Erwägungen insbesondere auf den Aufsatz Wert und Ehre der deutschen Sprache.

15 Sowohl im Alten als auch im Neuen Testament wird der Einbruch des Göttlichen in die Welt der Menschen mit dem Attribut des Schrecklichen, Furchteinflößenden belegt. „Dieser Furchtcharakter gehört wesentlich zur atl. Epiphanie; er ist nicht wie bei der Antike ein Symptom neben anderen, sondern gibt ihr weitgehendst das Gepräge. Selbst wenn die Epiphanien eine frohe Botschaft bringen (Gen 28, 17), reagiert der Mensch zunächst in der gleichen Weise, weil er stets den Einbruch des Göttlichen in seine Welt fühlt, woraus sich die große Bedeutung der Formel „Fürchte Dich nicht“ erklärt, die bis ins Neue Testament nachwirkt.“" (PAX 1955:136). 
Chandos-Brief den bildhaften Charakter jeder Wahrnehmung, die ,optische Oberflächenrealität“" (BOHRER 1981:65). Dieses Zurückgeworfen-Sein auf die Oberfläche der Dinge wird bereits von NIETZSCHE (1973:15) vorgedacht, wenn er in der Fröhlichen Wissenschaft schreibt, die Griechen seien aus Tiefe oberflächlich gewesen. (NIETZSCHE 1973:15) ${ }^{16}$ Die Philosophie Nietzsches - und vor ihm bereits Schopenhauers - hat somit eine wichtige Umwertung vorgenommen: Die Oberfläche der gegenwärtigen Wirklichkeit wird philosophisch als eine unbewusste, aber unaufhaltsam vorwärts treibende Dynamik am Grunde der Welt gedeutet, Oberfläche und Tiefe des Lebens werden somit zusammengedacht. Wenn HoFMANNSTHAL (1979/II:497) im Gespräch über Gedichte schreibt: „Wollen wir uns finden, so dürfen wir nicht in unser Inneres hinabsteigen: draußen sind wir zu finden, draußen.“, so kehrt diese Wendung nach außen das Novalis'sche Diktum um, das besagt: „Nach Innen geht der geheimnisvolle Weg. In uns oder nirgends ist die Ewigkeit mit ihren Welten, die Vergangenheit und Zukunft." (NovALIS 1983:279) Gleichzeitig wird das in Novalis' methodologischer Anleitung freigesetzte, utopische Potential unseres Hier-und-Jetzt-Gefühls (BOHRER 2003:63) noch einmal aufgerufen und in den Kontext der Sprachreflexion der Moderne gestellt. Michel FouCAULT (1966:791) charakterisiert in seinem Aufsatz über das ,Denken des Draußen“ diesen Paradigmenwechsel folgendermaßen: das ,Sprechen vom Sprechen' führe uns durch die Literatur, aber vielleicht auf anderen Wegen auch zum Draußen, dahin, wo das sprechende Subjekt verschwindet, während das ,Denken vom Denken“ mit seiner noch älteren Tradition als der der Philosophie gezeigt habe, dass es uns in die tiefste Innerlichkeit führt.

Bohrers Ansatz scheint dazu geeignet, Phänomene zu beschreiben, deren struktureller Aufbau für die Definition der Epiphanie relevante Kriterien wie Plötzlichkeit, Gegenwartsbezogenheit und Offenbarung oder Erleuchtung unter umgekehrtem Vorzeichen aufrufen. Es handelt sich hier um die literarische Gestaltung von Erlebnissen, die im Modus epiphanischer Offenbarung nicht Erkenntnisfülle und harmonische Verbundenheit von Ich und Welt, sondern Ich-Dissoziation und Disharmonie mit der Umwelt zur Darstellung brin-

16 Zur Ablehnung von Tiefe und der Konfrontation mit der Oberfläche der Realität in modernen Epiphanien vergleiche auch CHARLES TAYLOR (1994:809) in seiner umfangreichen Studie über die Entstehung der neuzeitlichen Identität. Taylor führt dieses Bedürfnis auf den Erfahrungsverlust in der modernen, instrumentellen Gesellschaft zurück: um „die echte Erfahrung wiederzuerlangen,“ sei es notwendig, ,an die Oberfläche der Dinge zurückzukehren“. 
gen. Die Reaktion auf diese Erfahrung kann von Angst und Schrecken und momenthafter Ich-Destabilisierung bis zum vollständigen Ich-Verlust führen. In diesem Zusammenhang wird die von Nietzsche vollzogene Wendung des Erhabenen zum ästhetisch sublimierten Schock virulent (BOHRER 1981:132f., 200f.). Das Erschrecken wird mit dem Zerbrechen des , principium individuationis ' assoziiert, das Subjekt muss seine eigene Entgrenzung im Großen und Ganzen des unbewussten Lebens lustvoll durchlaufen (BOHRER 2003:113f.). In der klassischen Moderne betrifft das Erhabene nicht die Darstellung eines Undarstellbaren, sondern eine Epiphanie, die plötzlich einfällt und die gewohnten Beziehungen zur Wirklichkeit untergräbt (BOHRER 2003:76-79). Gesucht wird Präsenz, die Erscheinung des Erscheinens selbst:

Erst wenn das Subjekt sich verliert, wenn es aus den pragmatischen Raum-ZeitErfahrungen ausschert, vom Schock des Plötzlichen berührt wird, die Sehnsucht nach der wahren Präsenz [...] erfüllt sieht und selbstverloren im Augenblick aufgeht [...] - erst dann öffnet sich die Welt des Unvorhergesehenen und schlechthin Überraschenden, der Bereich des ästhetischen Scheins, der weder verhüllt noch offenbart, weder Erscheinung noch Wesen ist, sondern nichts als Oberfläche. (HABERMAS 1985:116) ${ }^{17}$

So spricht MAURICE BLANCHOT (1982:138) vom „lockenden Reiz des reinen Augenblicks“, „,das nichts bedeutende abstrakte Aufblitzen, das keine Dauer hat, nichts zum Vorschein bringt und in das Nichts, das von ihm beleuchtet wird, zurückkehrt“". In diesem asignifikanten Moment, in dem das Nichts hervortritt, um erneut zu verlöschen, konzentriert sich der Unterschied zwischen den romantischen und den modernen Epiphanien, in denen sich auch der Sinn des Erhabenen umkehrt: Von der Erhebung des Subjekts geht er zur Konfrontation mit dem Anderen über. Für Bohrers Plötzlichkeitsbegriff ist Hofmannsthal paradigmatisch, wobei er den Moment der Plötzlichkeit vor allem in den Erzählungen ausfindig macht. Hier sei Narrativität im Sinne von Kontinuität nicht mehr vorhanden, der Augenblick wirke vielmehr gattungsauflösend, denn die ,unerhörte Begebenheit“, die sich der Goetheschen Theorie zufolge in der Novelle zutragen müsse, sei reduziert zum Augenblick, der sich zwar ereigne, dessen Inhalt aber höchst unklar bleibe (BOHRER 1981:62). Auch in Gedichten wie Erlebnis, die den schockhaften Rückblick auf das zurückliegende Lebensstadium der eigenen Kindheit und die plötzliche Erkenntnis der eigenen Kontinuität gestalten, die nur noch gewusst,

17 „In der ästhetischen Erfahrung wird die dionysische Wirklichkeit durch eine ,Kluft des Vergessens“ gegen die Welt der theoretischen Erkenntnis und des moralischen Handelns, gegen den Alltag abgeschottet.“ (HABERMAS 1985:116). 
nicht mehr aber erlebt werden kann, kann ein solcher Moment der Plötzlichkeit ausgemacht werden (HOFMANNSTHAL 1979/I:19). ${ }^{18}$ Durzak analysiert den Augenblick in Hofmannsthals Erzählungen unter dem Gesichtspunkt der Plötzlichkeit und beruft sich dabei auf Bohrer, verschiebt allerdings den Fokus: Das einem inneren Abgrund entspringende ,namenlose Erschrecken münde in diesen narrativen Texten in den ,glücklichen Augenblick der Lebenserfüllung, der für einen Bruchteil eine der Vergänglichkeit verfallene Welt in das ewige Diesseits eines arkadischen Paradieses entrückt" (DURZAK 1984:400f.). In solchen Augenblicken wird die Erschrecken auslösende Plötzlichkeit zum Modus der Erkenntnis, indem ein Kulminationspunkt der Gegenwart konstituiert wird, in dem ein das Leben einengender Erkenntnismoment aufscheint und das ganze Nacheinander des Lebensweges in das Jetzt einer Erkenntnisganzheit gezwungen wird. Das im prägnanten Augenblick des Plötzlichen erfolgende Erkennen bündelt den ganzen Lebensverlauf zu einer Einheit. Die formlose Zeit wird besiegt (DURZAK 1984:400f.).

\section{Der Augenblick als strukturbildendes Element in den Auf- zeichnungen und Tagebüchern}

„Immer wieder“, schrieb Hofmannsthal, „komme ich auf diesen für mein innerstes Leben so bedeutungsvollen Rätselbegriff der Zeit - und dieser Begriff ist es eben, der in unserer Zeit eine Wandlung durchmacht, und von dieser Wandlung müssen wir erfassen, daß wir ein neues Zeitalter zu betreten im Begriff sind.“" ${ }^{\text {"19 }}$ An Carl J. Burckhardt schrieb er: „Ich habe mich lebenslang mit dem was man ,Zeit' nennt (in den mehrfachen Bedeutungen des Wortes) herumgeschlagen, und ich möchte nicht sterben, ohne diesem Gegner, der etwas schlangenartig umschlingendes hat, noch mehr ins Gesicht gesehen zu haben. " ${ }^{20}$ Die Zeit kann demzufolge als ein Leitthema in Hofmannsthals Dichtungen betrachtet werden, wobei die um die Jahrhundertwende sich vollziehenden Wandlungen im Zeitdenken dem Schreiber bewusst sind (KOBEL 1970:2; REY 1968:165f.). Hofmannsthals Aufzeichnungen dokumentieren die

18 Vgl. ebenfalls das Gedicht Ballade des äußeren Lebens, in dem ein Ich sich selbst „,wie ein Hund, unheimlich stumm und fremd“" gegenübertritt. (HoFMANNSTHAL 1979/I:23)

19 Aus einem unveröffentlichten Brief vom 18. November 1928 (zit. nach KoBEL 1970:2).

20 Brief vom 29. November 1927 (zit. nach KoBEL 1970:2). 
tiefe Identitätskrise, die JACQUES LE RIDER (2001:15) als symptomatisch für die Tagebuchliteratur der Wiener Moderne ansieht. Sie scheinen somit den Zusammenhang zwischen den radikalen Neuerungen der Wiener Moderne in Philosophie, Kunst und Naturwissenschaften und dem Aufblühen der Textgattung Tagebuch eindrücklich zu belegen. ${ }^{21}$ Auch RALPH RAINER WUTHENOW (1990:110) zufolge prägen die Fragwürdigkeit des Ich und die damit verbundene Diskontinuität die Tagebücher. So lesen wir in einer Aufzeichnung aus dem Jahre 1894 von der „Auflösung der Seele in tausend Einzelsensationen“ (HOFMANNSTHAL 1980:379) und an anderer Stelle: „Das Individuum ist unaussprechlich.“ (HOFMANNSTHAL 1980:560) Eine Tagebucheintragung vom 5. Mai 1891 reflektiert über den rein pragmatischen Wert der Kategorie des Ich:

Wir erscheinen uns selbst als strahlenbrechende Prismen, den anderen als Sammellinsen (unser Selbst ist für uns Medium, durch welches wir die Farbe der Dinge zu erkennen glauben, für die andern etwas Einförmiges, Selbstfärbiges: Individualität; wir schließen aus dem Eindruck auf die Außenwelt, die andern aus dem Eindruck, den wir empfangen, auf unsere aufnehmende Substanz). (HOFMANNSTHAL 1980:329)

Der Zugang zu den Dingen der Außenwelt über die Bündelung unserer Wahrnehmungen in einer Ich-Instanz - eines reflexiven Selbst - bleibt illusorisch. Dem Selbst ist nur in Bildern auf die Spur zu kommen, wobei dem metaphorischen Vergleich mit strahlenbrechenden Prismen oder Sammellinsen hier eine zusätzlich relativierende Funktion zukommt, denn er trifft ja das Gemeinte nur scheinbar. So wie es in der Außenwelt nur noch disparate Dinge gibt, besteht das Innere - hier folgt Hofmannsthal den Lehren Ernst Machs - aus zusammenhangslosen Empfindungen. ${ }^{22}$ Identität ist nicht fassbar: 1903 schreibt HofMANNSTHAL (1979/II:497) im Gespräch über Gedichte: „Wir besitzen unser Selbst nicht: von außen weht es uns an, es flieht uns für lange und kehrt uns in einem Hauch zurück. Zwar - unser Selbst! Das Wort ist solch eine Metapher." In den Tagebüchern nennt er das Ich eine „Menagerie von Seelen“, im Menschen sei ,alles zugleich: Schwere und Bewegung, Mordlust und stilles Keimen, Möwenflug, Eisenklirren, schwingende Saiten, Blumenseele, Austernseele, Pantherseele ..." (HofMAnNSTHAL 1980:332). Dementsprechend kritisch setzt sich Hofmannsthal in seinen Auf-

21 Der Autor operiert allerdings, um seine Thesen zu belegen, mit sehr weitgesteckten und daher unpräzisen Gattungszuordnungen.

22 Der starken Einwirkung der Philosophie Ernst Machs auf Hofmannsthals Denken ist GOTTHART WUNBERG (1965) minutiös nachgegangen. 
zeichnungen und Tagebüchern mit dem Gedanken der Kontinuität auseinander: „Mein Ich von gestern geht mich so wenig an wie das Ich Napoleons oder Goethes." (1980:333) Kontinuität ist nur als physische gegeben, nicht jedoch als Möglichkeit der zeitlichen Ausdehnung von Erfahrung, die immer an den Augenblick gebunden bleibt. Das Tagebuch stellt klar: „Wir sind mit unsrem Ich von Vor-zehn-Jahren nicht näher, unmittelbarer eins als mit dem Leib unserer Mutter. Ewige physische Kontinuität.“ (1980:376) Der Körper wird in Hofmannsthals Reflexionen zu einer Verklammerung des Heterogenen. So kann der Schreiber im Buch der Freunde die Einheit des Ich in Frage stellen:

Der Hauptunterschied zwischen den Menschen im Leben und den erdichteten Figuren ist dieser, daß die Dichter sich alle Mühe kosten lassen, den Figuren Zusammenhang und innere Einheit zu geben, während die Lebenden in der Inkohärenz bis ans Äußerste gehen dürfen, da ja die Physis sie zusammenhält. (HoFMANNSTHAL 1980:285)

Der Schreiber ist somit auf den Augenblick zurückgeworfen, denn Leben kann nicht über den Moment hinaus konserviert werden. „Alles Gelebte schmeckt sonderbar und gräßlich wie Brackwasser: Tod und Leben gemischt" schreibt HOFMANNSTHAL (1980:260) im Buch der Freunde. ${ }^{23}$ Auch in den Tagebüchern wird der Augenblick zunächst auf den Moment der Wahrnehmung reduziert, in dem die Wirklichkeit sich nur scheinbar objektiv darstellt: „Wir haben kein Bewußtsein über den Augenblick hinaus, weil jede unsrer Seelen nur einen Augenblick lebt. Das Gedächtnis gehört nur dem Körper: er reproduziert scheinbar das Vergangene, d.h. er erzeugt ein ähnlich Neues in der Stimmung. “ (HofMANNSTHAL 1980:333) Hofmannsthal nimmt hier Gedanken aus der dramatischen Studie Gestern aus dem Jahre 1891 auf, in der Zeit in eine heterogene Folge voneinander unabhängiger Jetzt-Punkte aufgelöst wird (KoBEL 1970:6f.). Andrea versucht der Drohung der Vergänglichkeit zu entgehen, indem er die Zeit als Kontinuität leugnet, für ihn trennt ein Abgrund das Gestern und das Morgen vom Heute (HoFMANNSTHAL 1979/I:218). Er empfindet sich als „des Augenblickes Knecht“ (1979/I:238), da er diesen nur als Moment der Vergänglichkeit wahrnehmen kann. So zeugt der Augenblick in Gestern einerseits von der Auflösung des

23 Vgl. ebenfalls die Eintragung ins Tagebuch vom Mai 1910, in der HofMANNSTHAL (1980:554) sich einer ähnlichen Metaphorik bedient: „Alles Gelebte ist in der Erinnerung von einer Sonderbarkeit, die dem Traum nahe kommt; seine Wiederannäherung zieht an und stößt ab, - in ihr mischt sich Tod und Leben wie süßes und salziges Wasser an der Mündung der Flüsse. 
Subjekts, wird jedoch andererseits zum Ort der Selbstbewahrung: „Laß dich von jedem Augenblicke treiben, / Das ist der Weg, dir selber treu zu bleiben; / Der Stimmung folg, die deiner niemals harrt, / Gib Dich ihr hin, so wirst Du Dich bewahren.“ (1979/I:218) Es vollzieht sich hier eine ungeheure Bedeutungsaufwertung des Augenblicks als des letzten Ortes, an dem das Subjekt seiner selbst habhaft werden kann. ${ }^{24}$

In den Tagebüchern findet eine intensive Auseinandersetzung mit Positionen des Ästhetizismus statt. ${ }^{25} 1891$ tadelt HoFMANNSTHAL (1980:321) „Amiels Versinken in die Unendlichkeit der Ursachen; verwandt damit das willenlose Hinfluten des modernen Menschen in der Empfindung“. ${ }^{26}$ Die Gefahren eines passiven Hingegebenseins an die Kontemplation über das Leben werden im Text Der Dichter und diese Zeit zum Ausdruck gebracht:

Er (der Künstler) ist da und wechselt lautlos seine Stelle und ist nichts als Auge und Ohr und nimmt seine Farbe von den Dingen, auf denen er ruht. Er ist der Zuseher, nein, der versteckte Genosse, der lautlose Bruder aller Dinge, und das Wechseln seiner Farbe ist eine innige Qual: denn er leidet an allen Dingen, und indem er an ihnen leidet, genießt er sie. Dies Leidend-Genießen, dies ist der ganze Inhalt seines Lebens. Er leidet, sie so sehr zu fühlen. (HoFMANNSTHAL 1979/III:67)

Das lyrische Drama Der Tod des Tizian beinhaltet die vielleicht prägnanteste Formulierung des Ästhetizismus: ,[...] jedes Tages Fließen / Und Fluten als ein Schauspiel zu genießen, / Die Schönheit aller Formen zu verstehen / Und unsrem eignen Leben zuzusehen.“ (HofmanNSTHAL 1979/I:256) Aus der Distanzierung von den Tagebüchern Amiels, der in seiner narzisstischen Verfangenheit in sich selbst „am ungelebten Leben“ scheiterte (WUTHENOW 1990:82f.), beziehen die Tagebuchaufzeichnungen die ihnen eigene Ironie, und HOFMANNSTHAL (1980:541) pointiert: „Frauen forschen lange und aufmerksam im Spiegel, Männer forschen lange und aufmerksam in Büchern; das Ziel ist das gleiche: sich schöner werden zu sehen." Dieses Gefühl, willen- und wehrloses Objekt seiner Eindrücke und Empfindungen zu sein, kennt Hofmannsthal aus eigener Erfahrung. So schreibt er 1895 an seinen Vater:

24 Zur Weiterentwicklung des Verständnisses der Vergänglichkeit bei Hofmannsthal vgl. BAUMANN (2007:223-238).

25 Hier liegt für Wuthenow (1990:111) der Schwerpunkt der Tagebücher Hofmannsthals.

26 Vgl. ebenfalls den Aufsatz Hofmannsthals über Amiels Tagebücher: Das Tagebuch eines Willenskranken. (HOFMANNSTHAL 1979/III:106-117) 
[...] nach meiner Anschauung liegt im Ausüben der Künste nichts anderes als das Bestreben, sich die Gegenwart zu multiplizieren dadurch, daß man sich fremdes Leben aneignet und die eigene Gegenwart durch Reflexion ganz auslebt, die entschwundene wieder hervorruft. Denn da Zeit etwas höchst Relatives, eine bloße Anschauungsform unseres Geistes ist, so kann man wirklich in einen Augenblick unendlichen Gehalt legen, und ich bin der festen Überzeugung, daß ich tatsächlich manchmal bei einer Fahrt mit der Tramway mehr erlebe als ein anderer auf einer Reise. (Zit. nach GRUNDMANN 2003:7)

Während hier noch die Potentialität des Augenblicks, die in seiner schier unendlichen Auffaltung begründet ist, gepriesen wird, stellt das lyrische Drama Der Tor und der Tod dar, wie Ästhetizismus und überbordende Reflexion das Leben im Augenblick unmöglich machen.

In den Aufzeichnungen wird die Formlosigkeit des gegenwärtigen Augenblicks als Problem der literarischen Gestaltung reflektiert. Aus dem Jahr 1890 stammt die folgende Eintragung: „Wir verstehen nur uns selbst, und an uns selbst nur das Gegenwärtige, und auch den gegenwärtigen Gedanken nur solang, als wir ihn denken, als er flüssig ist.“ (HofMANnSTHAL 1980:316) Der spontan erlebte Augenblick verflüchtigt sich in der Sprachwerdung. Den Gedanken, dass die Potentialität des Augenblicks abgetötet wird, sobald er an die Grenzen des Wortes stößt (SCHOPENHAUER 1947:539), finden wir in den Gedichten wieder. In Sünde des Lebens aus demselben Jahr lesen wir: „Denn was dein Geist, von Glut durchzuckt, gebar, / Eh dus gestaltet, ists schon nicht mehr wahr." (HoFMANNSTHAL 1979/I:103) Auch im Gedicht Wolken hat sich das Gefühl der Vergänglichkeit zu höchster Flüchtigkeit gesteigert: „Wogende Bilder, / Kaum noch begonnen, / Wachsen sie wilder, / Sind sie zerronnen“. (HOFMANNSTHAL 1979/I:126)

Der Anspruch, im Tagebuch zu einer der Welterfahrung der Moderne angemessenen Darstellungsform des Ich zu gelangen, wird jedoch nicht aufgegeben, sondern gerade in der Abgrenzung vom ausufernden Augenblick Amiels entwickelt, dessen Tagebücher Hofmannsthal „mit unsäglicher Sehnsucht nach Begrenztem, nach scharfen Konturen, nach greifbarer, gemeiner Deutlichkeit“" gelesen habe. (HofMANNSTHAL 1980:332) In den Notizen lässt sich der Weg zu einer neuen Poetik des Tagebuchs nachvollziehen, denn ästhetizistischen Positionen gegenüber sei es „Pflicht sich zu beschränken, im Schaffen und Denken mit dem Fragmentarischen sich zu begnügen, auch das Gefühl zu begrenzen“ (HofMAnNSTHAL 1980:321). Als Vorbild schweben ihm die Tagebücher Hebbels vor. Kurz darauf folgt noch diese Bemerkung: „Künstler lieben vollendete Kunstwerke nicht so sehr wie Fragmente, Skizzen, Entwürfe und Studien, weil sie aus solchen am meisten fürs Handwerk 
lernen können.“ (HofMAnNSTHAL 1980:331) Auch auf struktureller Ebene wird in den zum Fragment und Aphorismus tendierenden Aufzeichnungen ein Schreibprogramm der Reduktion und komprimierender Verknappung realisiert. Bereits im Buch der Freunde fordert der Schreiber zeitliche Begrenzung ein: „Eine Stunde Betrachtung ist besser als ein Jahr Andacht.“ (HOFMANNSTHAL 1980:257) Vorbild in der sprachlichen Erfassung des Augenblicks sind ihm unter anderem die Fragmente von Novalis, die imstande seien, das Flüchtige von Erkenntnis in sich zu bergen und so die Zeit zu besiegen. (HOFMANNSTHAL 1980:292) Auch in Hebbels Gedichten findet der Schreibende eine „grandiose Lebenskristallisation“ (HOFMANNSTHAL 1980:294). Das Streben nach Fokussierung in der literarischen Gestaltung entspringt dem Bedürfnis nach Konturierung des eigenen Lebens in klar voneinander abgrenzbaren Augenblicken: „Indem ich mich über mein Leben beuge und mich bestrebe, es darzustellen, so ist es voller Form und entzieht sich doch der Form. Ich erlebe nichts einzelnes: alles ziehet einander herbei.“ (Hofmannsthal 1980:432) Das moderne Lebensgefühl, dem der Schreiber in Tagebuch und Aufzeichnungen eine angemessene Form verleihen will, speist sich aus der Erfahrung, aus dem Ganzen des Lebens ${ }^{27}$ herausgefallen zu sein, und dem Wunsch nach Restituierung dieser ursprünglichen Einheit. ${ }^{28}$ Die frühen Eintragungen zeugen von Hofmannsthals Bemühen, aus seinem Jugenderlebnis des All-Einen gerade für die innere Haltlosigkeit Kraft zu schöpfen. So notiert er 1893 im Tagebuch: „Der tragische Grundmythos: die in Individuen zerstückelte Welt sehnt sich nach Einheit, Dionysos Zagreus will wiedergeboren werden.“ (HoFMANNSTHAL 1980:359) Dieses Zurückstreben zur Prä-Existenz, das sich bis in die späteren Notizen erhält ${ }^{29}$, verbindet sich in den Tagebüchern mit einer maximalen Bündelung und Fokussierung: „Den Gedanken scharf fassen: Wir sind eins mit allem, was ist und was je war [...].“ (HofMANNSTHAL 1980:376) In den Tagebüchern wird der Kontakt mit dem Ganzen in Augenblicken blitzartiger Erkenntnis erprobt und ist Gegenstand aphoristisch zugespitzter Eintragungen: „Mit den Gedanken ist es wie mit den Melodien; es gibt die kurzen, geringen - und die langen, schönen; die besten aber sind wie Kugelblitze und enthalten die Welt im Ganzen.“

$27 \mathrm{Zu}$ Hofmannsthals von Dilthey und Nietzsche geprägtem Lebensbegriff vgl. BOLLNOW (1949:50-55).

28 „Wir leben in einem abgeleiteten Zustand. Alles die Nachwirkungen eines primären erhöhten Daseins." (HoFMANNSTHAL 1980:397)

29 Noch 1922 stellt Hofmannsthal fest: „Als junger Mensch sah ich die Einheit der Welt."(HOFMANNSTHAL 1980:618) 
Beate Sommerfeld

(HofMANNSTHal 1980:566) Der wandernde Blitz steht hier als Metapher für die zeitliche Ausdehnung blitzartiger, plötzlicher Erkenntnis, während die Form der Kugel mit dem zu erfassenden „Ganzen“ korrespondiert.

Der gegenwärtige Augenblick wird als Herausfallen aus der Prä-Existenz Haltlosigkeit und als unsicher erlebt, wobei dies eine Ambivalenz in sich birgt: „In der Gegenwart ist immer jenes verborgen, durch dessen Hervortreten alles anders werden könnte: das ist ein schwindelerregender Gedanke, aber ein trostvoller.“ (HofMANNSTHAL 1980:585) Die Haltlosigkeit des gegenwärtigen Augenblicks wird hier als Kondition des modernen Menschen bejaht, sogar als eigener Wert und Chance begriffen. Der fehlende Zusammenhang im Leben des modernen Menschen kann nur durch besondere, herausgehobene Augenblicke von höchster fragiler Konsistenz kompensiert werden, die Hofmannsthal in den Aufzeichnungen beschwört: „Die wenig Zusammenhang in sich selber fühlen, reden vom Festhalten an den Ideen. Die Ideen sind aber nichts, woran man festhalten könnte; sie sind ein Jenseitiges, das sich uns in höchsten Augenblicken enthüllt und sich wieder entzieht.“ (Hofmannsthal 1980:257) Der Konturierung dieser „höchsten Augenblicke" werden in den Aufzeichnungen einige prägnant formulierte Sätze gewidmet, die vor dem Hintergrund der sog. Chandos-Krise verständlich werden. Im Chandos-Brief kommt die Priorität der äußeren Dinge zum Tragen: Je weniger sich das Ich besitzt, desto mehr braucht es das Außen, die Berührung mit den mystisch interpretierten Dingen. Es kommt eine SubjektObjekt-Fusion zustande, in der eine besondere Zeitebene entsteht, eine Gleichzeitigkeit, in die sowohl Vergangenheit als auch Zukunft eingehen. ${ }^{30}$ Die epiphane Struktur dieser Augenblicke entsteht durch die Vernichtung des Ich, das sich selbst für einen Augenblick vergessen kann. ${ }^{31}$ Inmitten der im Subjekt sich ausweitenden Leere, indem es sich dieser Leere aussetzt, scheinen glückliche Augenblicke auf, indem das Ich sich nach außen wendet: „draußen sind wir zu finden, draußen“ (HOFMANNSTHAL 1979/II:497) ${ }^{32}$, da-

30 (WELLBERRY 2007:190f.); Wellberry konstatiert an dieser Stelle eine Gemeinsamkeit zwischen zentralen Denkfiguren Hofmannsthals und Schopenhauers.

31 Zum ,sakrifiziellen' Ursprung dieser Augenblicke, die als archaisch-gewaltdurchtränkte Augenblicke der Opferung beschrieben werden und in denen das Subjekt „die Gegenwart des Unendlichen durchschauert“, vgl. WellBERRY (2007:205).

32 Zur Wendung von Innen nach Außen und die im Gespräch über Gedichte enthaltenen Verweise auf etwas außerhalb der Wörter Liegendes, die Hinwendung zu den Dingen vgl. BOHRER (1994:71-75). 
hin, wo das sprechende Subjekt verschwindet (FOUCAULT 1966:791). Im Bild der Wirbel, ,durch die hindurch man ins Leere kommt" (HofMANNSTHAL 1979/II:466), wird der Prozess der Verselbstständigung der Sprache mit einer auf mystische, außersprachliche Weise und erst nach dem Zusammenbruch der naiven Ganzheitsgewissheit der Prä-Existenz im Modus der Epiphanie erfahrbaren Wirklichkeit verbunden. (GÖTTSCHE 1987:98) In den Aufzeichnungen pointiert der Schreiber dementsprechend: „Aus lauter Leeren ist die Fülle der menschlichen Existenz aufgebaut.“ (HOFMANNSTHAL 1980:267) Die Berührung mit den Dingen wird nun zum Impuls dieser glücklichen Augenblicke. Die Dinge werden, indem sie aufscheinen ,für eines Gedankenblitzes Dauer“ (HofMANNSTHAL 1979/II:503), zum Träger von Epiphanien. Eintragungen, in denen zunächst beiläufig notierte Beobachtungen plötzlich grell ,belichtet" werden, erscheinen im Tagebuch häufig. Die Beschreibungen von „kleine(n) Sache(n)“ gehen in eine Vision über, die das Lebensganze „für einen Augenblick aufschließt und dann wieder verlöschen läßt“ (HOFMANNSTHAL 1980:384). Das aufstrahlende Objekt bewirkt einen Erkenntnisblitz im betrachtenden Subjekt:

Epiphanie [...] bezieht sich zunächst auf ein äußeres Erscheinungsbild, auf die Registrierung der Oberfläche, was durch die Sinne in einem bestimmten, konzentrierten Moment wahrgenommen wird, nimmt durch die Erscheinung Umrisse an. Im gleichen Vorgang aber wird Epiphanie als wahrgenommener Moment auch schon Erscheinung = Vision, vorgestellter Moment, der die einzelne Wahrnehmung von einem anvisierten Ganzen her aufleuchten, ,strahlen läßt. (HÖLLERER 1961:127)

Auch diese Einsicht wird in den Aufzeichnungen als Paradoxon formuliert: „Die Tiefe muß man verstecken. Wo? An der Oberfläche.“ (HofMANNSTHAL 1980:268) Diese sinnhafte Freisetzung der Wirklichkeit verdichtet sich in einem Wirbel, ,aber solche, die nicht wie die Wirbel der Sprache ins Bodenlose zu führen scheinen, sondern irgendwie in mich selber und in den tiefsten Schoß des Friedens" (Hofmannsthal 1979/II:471). In dieser Entdeckung verschütteter Wirklichkeitsdimensionen findet sich Chandos als Subjekt wieder (GÖTTSCHE 1987:98). In den Aufzeichnungen schreibt HOFMANNSTHAL (1980:299) dementsprechend: „Die reinste Poesie ist ein völliges Außer-sichsein“, und „Die Welt will einen jeden aus ihm selbst herausreißen und wieder zu ihm selbst bringen.“ (1980:261) Man müsse sich selbst in einen „hohe(n) erregte(n) Zustand“ versetzen, um von außen ,die Elemente des kugelförmigen Daseins“ zugeführt zu bekommen (1980:394). Die stete Bewegung von Verlieren und Wiedergewinnen seiner selbst wird in den Briefen eines Zurückgekehrten beschrieben, wo sie durch das Betrachten der Bilder van 
Goghs motiviert wird: ,[...] daß ich das Gefühl meiner selbst an diese Bilder verlor, und mächtig wieder zurückbekam, und wieder verlor!“ (HofMANNSTHAL 1979/II:564f.) Sie wird ähnlich wie im Chandos-Brief im Modus des Plötzlichen erlebt, der zwar die Unmöglichkeit sprachlicher, narrativer Vermittlung impliziert, andererseits aber auch eine sprachliche Pointierung initiiert: „Wie aber könnte ich etwas so Unfaßliches in Worte bringen, etwas so Plötzliches, so Starkes, so Unzerlegbares.“ (HofMANNSTHAL 1979/II:565) Die Aufzeichnungen zeugen ebenfalls von dem Streben nach Konturierung des Augenblicks, indem die Vielheit der Empfindungen in Augenblicken der Plötzlichkeit gebündelt wird, dem „Schwindel, [...] wobei man plötzlich über die ganze Existenz staunt“ (Hofmannsthal 1980:358). In der Aufzeichnung „Die Sprache“ erscheint die unmittelbare Erfahrung des Lebens als einer dieser erschreckenden Augenblicke der Plötzlichkeit. „Wenn sie (die Sprache) wie ein ebbendes Meer zurücktritt, das nackte Gerüste Leben entblößt - solche Augenblicke ertragen wir kaum." (Hofmannsthal 1980:413) Momente der Haltlosigkeit, hervorgerufen durch den plötzlichen Einblick ins Innere der Welt werden in Lektüren gesucht und im Tagebuch vermerkt, beispielsweise in der folgenden Notiz: „Darstellung bei Richard. - Es ist für Augenblicke, als würde die Schale der Erde unter einem zu Kristall und ..." (HofMANNSTHAL 1980:368). Indem er die Eintragung unvermittelt abbrechen lässt, markiert der Schreiber das Zurückweichen vor dem Schrecken dieser Erfahrung und lässt gleichzeitig dem Unsagbaren Raum. Auch dem unkonturierten und sprachlich nur schwer zu gestaltenden Phänomen der Vergänglichkeit des Lebens versucht Hofmannsthal als Tagebuchschreiber gerecht zu werden, indem er das Erkennen der Vergänglichkeit narrativ als Ereignis gestaltet: „Heute war im Kasernenhof Schnee, dann taute es und war Kot und ein Wind, wie im März. ,Mein Frühling“, sagte ich vor mich hin und hatte bis zum Weinen das Bewußtsein der Vergänglichkeit des Lebens.“ (Hofmannsthal 1980:388) Das Bemühen, das Bewusstsein der Vergänglichkeit als Schock darstellbar zu machen, wird auch in einer Tagebucheintragung deutlich, in der sich Hofmannsthal einen Augenblick herbeiwünscht, in dem ihm ,der immer gegenwärtige Gedanke der Vergänglichkeit mit besonders entsetzlicher Gewalt ins Leben träte." Dieser vom Schreiber imaginierte Vergänglichkeitsschock soll als der Ausgangspunkt zum Verfassen eines Dramas produktiv gemacht werden. (HOFMANNSTHAL 1980: 474) In einzelnen Eintragungen werden solche Augenblicke der Plötzlichkeit erzählerisch vermittelt:

Göding, am 14. VI. abends. - Kühl, hell und windig. Ich habe Wein getrunken. Bin dann ein Stück auf der Straße gegen Mutenitz sehr schnell gegangen. Plötz- 
lich unter einer großen Pappel stehengeblieben und hinaufgeschaut. Das Haltlose in mir, dieser Wirbel, eine ganze durcheinanderfliegende Welt, plötzlich wie mit straff gefangenem Anker an die Ruhe dieses Baumes gebunden, der riesig in das dunkle Blau schweigend hineinwächst. Dieser Baum ist für mein Leben etwas Unverlierbares. In mir der Kosmos, alle Säfte aller lebendigen und toten Dinge höchst individuell schwingend, ebenso in dem Baum. (HoFMANNSTHAL 1980:401)

Es handelt sich um eine als erlebt geschilderte Epiphanie des Tagebuchschreibers, in der sich eine der Alltäglichkeit enthobene Subjektivität manifestiert. Das präzise Vermerken des Zeitpunkts markiert das Herausgehobene dieses Augenblicks. Die mystische Erfahrung ist flüchtig, sie bedeutet nicht ,Leben' als Besitz und Zustand, wie dies in der Kindheit möglich war, als wie im Chandos-Brief formuliert - ,in einer Art von andauernder Trunkenheit das ganze Dasein als eine große Einheit“ (HoFMANNSTHAL 1979/II:464) erfahrbar war. Der plötzliche Blick wird hier als Erlebnis emphatisiert, das dem Subjekt alle lebendigen und toten Dinge der Außenwelt einverleibt. Die elliptischen Sätze evozieren das Unvorhersehbare des das Subjekt überfallenden Erlebnisses, die Unmittelbarkeit des Erlebnisses und auf der Ebene des Schreibens die Spontaneität des Notierten. Das Attribut der Plötzlichkeit wird sowohl auf das Erlebnis der erschreckenden Haltlosigkeit als auch die erneute Verankerung in der Welt bezogen: Wie in den Briefen eines Zurückgekehrten bezieht sich das Erlebnis der Plötzlichkeit gleichermaßen auf das Verlieren und das Wiedergewinnen seiner selbst. Das Subjekt muss sich zwei sukzessiven Schocks aussetzen: Sich - wie im Chandos-Brief dem Wirbel der Leere auszusetzen wird zur Voraussetzung für das Erlebnis der Einheit, der Verbindung des Ganzen mit dem Individuellen. ${ }^{33}$ In Eintragungen wie dieser wird der Augenblick zum Element einer narrativen Strukturierung des im Sinne Nietzsches emphatisch verstandenen, nur in Augenblicken erfahrbaren ,Lebens', in denen das Subjekt seine Identität auf dem Wege der Entgrenzung wiedergewinnt. Der Augenblick als Moment plötzlichen Erschreckens, als die Gattungsgrenzen aufsprengendes und literarisch schwer zu vermittelndes Erlebnis scheint für Hofmannsthals Schreibpraxis besonders produktiv zu sein. Bleibt das Erlebnis des plötzlich eintretenden Augenblicks aus, können die Dinge der Außenwelt - wie in der Eintragung einige Tage zuvor - nicht belebt werden: „Sehr große Depression. Abends Spaziergang im Wald, Birken, schwarzes Wasser, Sumpfgräser, alles

33 Kobel (1970:174f.) nennt diese „erhöhten Augenblicke“ Visionen der Zusammenschau und stellt damit Zweiteres in den Vordergrund. 
tot, ich mir selbst so nichts, so unheimlich. Alles Leben von mir gefallen.“ (Hofmannsthal 1980:401) Die Dinge stehen hier unverbunden nebeneinander und in der Stasis des Betrachtens kann das Subjekt keinen Bezug zu ihnen herstellen. In den Tagebüchern werden die Leere der Verlassenheit und die Fülle der Augenblicke immer wieder kontrapunktisch einander gegenübergestellt, so wie die erhöhten Augenblicke in Ein Brief nicht in Lebensvollzug überführt werden können: ,Leben “ wird grundsätzlich nur in Augenblicken erfahrbar. In der Beschreibung von Landschaften werden die Momente eines intensiven Naturerlebens als „Berauschung“ gekennzeichnet, die einen neuen Lebensabschnitt einleitet (HOFMANNSTHAL 1980:404, 405). Mit der Überwältigung durch ein furchterregendes Ereignis mit Erleuchtungscharakter und der Gestaltung der herausgehobenen Augenblicke als lebensgeschichtliche Zäsur aktualisiert Hofmannsthal weitere Strukturmerkmale von Epiphanien (PAX 1962:289f.).

Bei der Sammlung Ad me ipsum handelt es sich um ein eigenes Projekt innerhalb der Aufzeichnungen, in dem der Werdegang zum Dichter nachgezeichnet werden soll. Der Schreiber bemüht sich um einen Überblick über wichtige Themen und Problematiken der Jugendwerke, um sie in ihrem Zusammenhang erscheinen und Folgerichtigkeit erkennbar werden zu lassen: „Das Motiv des $\mathrm{Zu}$-sich-selber-Kommens in den Jungendwerken möge hier nachgewiesen werden, um den Schluß mit dem Anfang zu verbinden.“ (HoFmAnNSTHAL 1980:604) Die Notizen haben demzufolge raffenden, ordnenden Charakter. Der Augenblick soll ins Lebenskontinuum eingeordnet werden, der Schreiber möchte das Gleichgewicht herstellen zwischen „Sein und Werden“ (HOFMANNSTHAL 1980:590). Bezüglich der frühen Werke wird der Augenblick jetzt als Kulminationspunkt des Zeiterlebnisses exponiert. Das Plötzlichkeitserlebnis des Schreckens, der unvermittelte, Identität untergrabende Einblick in den „Abgrund der Zeit“, in dem das Ich sich selbst als Doppelgänger gegenübertritt, wird in $A d$ me ipsum zum Vehikel der Ganzheitserfahrung und Erhabenheit über eine zum „magischen Augenblick“ (Hofmannsthal 1980:604) gesteigerten Zeit. In Der Tor und der Tod sieht der Autor jetzt die „Unfähigkeit, jeden einzelnen Augenblick - oder mehr als einzelne Augenblicke - [...] ins Ewige zu heben“ (HofMANNSTHAL 1980:612). Hofmannsthal scheint hier auf ein Augenblicksverständnis zurückzugreifen, das er im Gespräch über Gedichte aus seiner Goethe-Lektüre bezieht und das den Schrecken der Abgründigkeit des menschlichen Lebens in sich aufhebt:

Und diese Abgründe, in denen das Leben sich selber verschlingt, kann ein Augenblick durchleuchten, entbinden, Milchstraßen aus ihnen machen. Und 
diese Augenblicke sind die Geburten der vollkommenen Gedichte, und die Möglichkeit vollkommener Gedichte ist ohne Grenzen wie die Möglichkeit solcher Augenblicke. (HofMANNSTHAL 1979/II:509)

Das Goethesche Beispiel der Wahlverwandtschaften scheint hier als Fluchtpunkt einer solchen Erhebung des Augenblicks nachzuwirken, zumal die Hoffnung über den vereinzelten Augenblick hinaus auf das Leben in seiner Dauer zielt. ${ }^{34}$ In einer mit „Leben“ betitelten Tagebucheintragung vom 1. Oktober 1906 schreibt Hofmannsthal in Anlehnung an Goethes Roman über die „unscheinbarsten Momente des Lebens“, in denen die Materie „,in die Sphäre der höheren reinen Bewußtheit" gehoben werden könne. In seiner Schilderung der Transposition dieser Momente greift HoFMANNSTHAL (1980:476) auf die Gestaltungsmerkmale der Epiphanie zurück: „Man kann jeden von ihnen gleichsam in seinem anderen Zustand, seinem eigentlichen Weltzusammenhange wie einen Rubin aufglühen sehen.“ Dieses plötzliche Erstrahlen (HÖLLERER 1961:127) eines im Modus der Epiphanie wahrgenommenen Objekts, wie Ottilie es bei der Betrachtung Eduards erlebt, wird zur Matrix einer Wahrnehmung (eines Augen-Blicks also) erhoben, die das Ich von Disparität heilen und Identität wiederherstellen soll:

[...] so müßte man sich selbst und seine Umgebenden erblicken können und die Gegenwart zu diesem abgeschiedenen mäßig erhellten, ohne Schmuck unsäglich schönen Raum erheben. [...] Auch die entferntesten Schicksale, die fremdesten Lebensäußerungen müßte man in diesem Medium erblicken können, wodurch sie sich auf ein zusammengefaßtes und völlig beruhigtes Ich bezögen. (HOFMANNSTHAL 1980:476)

$\mathrm{Zu}$ dieser Erhebung des gesamten Lebens über einzelne Augenblicke hinaus gelangt man durch sittliches Handeln (HoFMANNSTHAL 1980:476). Die Reflexionen über den erhöhten Augenblick der Inspiration hingegen sind in $\mathrm{Ad}$ me ipsum eher von Skepsis und Selbstironie geprägt: „Über die Wahl des Dichterberufes. Ein Mensch sitzt im Wald, schreibt 21 Gedichte. Er malt Gestalten hin, der Augenblick nimmt sie auf: und sein Schicksal ist entschieden. Aber er steht erst am Anfang eines harten Weges.“ (HoFMAnNSTHAL 1980:619) Diese Miniatur mit aphoristischem Charakter stellt die Erfahrung des Augenblicks an den Anfang der Entwicklung zum Schriftsteller. ${ }^{35}$ Der Augenblick erscheint hier lediglich als ,Rohmaterial ' des Schreibens, als des-

$34 \mathrm{Zu}$ Hofmannsthals Anlehnung an den Lebensbegriff Goethes vgl. BoLLNOw (1949:50f.).

$35 \mathrm{Zu}$ Hofmannsthals Streben nach Selbstinterpretation in Ad me ipsum vgl. KöNIG (1999:61-73). 
sen eigentliche Aufgabe die narrative Vermittlung von Augenblickseindrücken begriffen wird. ${ }^{36}$ In den Aufzeichnungen Ad me ipsum werden Augenblicksinspirationen voller Pietät in Erinnerung gerufen, jedoch auch als Allmachtsphantasie selbstkritisch reflektiert: „Die Offenbarungen, durch die Ausübung der Dichtkunst empfangen. - Die Augenblicke der Macht.“ (Hofmannsthal 1980:621) Der Schreiber rechnet hier mit dem elitären Erlebnis der Augenblicke ab, das nur eine Seite später als Versuchung zum Hochmut gekennzeichnet wird. (HofMANnSTHAL 1980:622) Empfunden wird in den Aufzeichnungen Ad me ipsum die Leere zwischen den Augenblicken, die Unmöglichkeit ihrer Überführung in Dauer: „Das unheimliche Vergessen von Augenblick zu Augenblick." (HoFMANNSTHAL 1980:613) ${ }^{37}$ Das autobiographische Projekt der Aufzeichnungen mündet am Ende in das Vorhaben, „gewisse Momente des eigenen Lebens darzustellen“ (HoFMANNSTHAL 1980:626) und sie ganz auszuloten: „Gerade die widerhaarigen Züge beachten, die scheinbar nicht ins Bild wollen, die ganz kleinen Details, die der Erinnerung entschlüpfen wollen, ihnen nachgehen; auch den sonderbarsten Assoziationen unermüdlich nachgehen.“ (HOFMANNSTHAL 1980:627)

\section{Literatur}

Bartmann, Christoph (1984): Suche nach Zusammenhang. Handkes Werk als Prozeß. Wien.

BAUMANN, GeRHART (2007): Continuität in der Vergänglichkeit - „von nichts ausgeschlossen. “ Hofmannsthals „Terzinen über Vergänglichkeit“. In: NEUMANN, GERHARD / RENNER, URSULA / SCHNITZLER, GÜNTHER / WUNBERG, GOTTHART (eds.): Hofmannsthal-Jahrbuch zur europäischen Moderne 15. Freiburg, 223-238.

Blanchot, Maurice (1982): Der Gesang der Sirenen. Frankfurt (M.)/Berlin/Wien.

BoHrer, KARL HeInZ (1981): Plötzlichkeit. Zum Augenblick des ästhetischen Scheins. Frankfurt (M.).

- (1994): Das absolute Präsens. Die Semantik ästhetischer Zeit. Frankfurt (M.).

- (2003): Ekstasen der Zeit. Augenblick, Gegenwart, Erinnerung. München/Wien.

Bollnow, ОтTо F. (1949): Zum Lebensbegriff des jungen Hugo von Hofmannsthal. In: Archiv für Literatur und Volksdichtung I:50-62.

36 Es wird hier ein Gedanke aus dem Buch der Freunde wieder aufgenommen, in dem darüber nachgedacht wird, wie man im Schreiben den schöpferischen Augenblick perpetuieren könne.

37 Die Bemerkung erscheint ein weiteres Mal in den Tagebüchern, allerdings ohne das Attribut „unheimlich“. (HOFMANNSTHAL 1980:558) 
Czajka, Anna (2006): Poetik und Ästhetik des Augenblicks. Studien zu einer neuen Literaturauffassung auf der Grundlage von Ernst Blochs literarischem und literaturästhetischem Werk. Anhang mit unveröffentlichten oder verschollenen Texten von Ernst Bloch. Berlin.

DuRZAK, MANFRED ( 1984): Der Augenblick als strukturbildendes Element der Kurzgeschichte. In: THOMSEN / HOLLÄNDER, 388-411.

ERZGRÄBER, WILLI (1984): ,The Moment of Vision“ im modernen englischen Roman. In: THOMSEN / HOLLÄNDER, S. 361-387.

Fischer, MARKus (1986): Augenblicke um 1900. Literatur, Philosophie, Psychoanalyse und Lebenswelt zur Zeit der Jahrhundertwende. Frankfurt (M.) u. a.

Foucault, Michel (1966): La pensée du dehors. In: Defert, Daniel / Ewald, FrançOIS (eds.): Dits et écrits. 1954-1988. Bd. 1. Paris, 789-821.

GillesPie, Gerald (1986): Epiphany: Notes on the Applicability of a Modernist Term. In: Riesz, JÁnos / Boerner, Peter / Scholz, Bernhard (eds.): ,Sensus communis '. Contemporary Trends in Comparative Literature. Tübingen, 255-266.

GÖTTSCHE, DiRK (1987): Die Produktivität der Sprachkrise in der modernen Prosa. Frankfurt (M.).

GotTwald, HeRwig (2003): Spuren des Mythos in moderner deutschsprachiger Literatur. Salzburg.

GRUENTER, Undine (1995): Der Autor als Souffleur. Frankfurt (M.).

Grundmann, HeIKe (2003): Mein Leben zu erleben wie ein Buch: Hermeneutik des Erinnerns bei Hugo von Hofmannsthal. Würzburg.

HABERMAS, JÜRGEN (1985): Der philosophische Diskurs der Moderne. Frankfurt (M.). HaCK, Аснім (1999): Epiphanie / Advent. In: Auffarth, Christoph et al. (eds.): Metzlers Lexikon Religion. Bd. 1. Stuttgart/Weimar, 277-280.

Hillebrand, BRUNO (1999): Ästhetik des Augenblicks. Der Dichter als Überwinder der Zeit - von Goethe bis heute. Göttingen.

HÖLlERER, WAlter (1961): Die Epiphanie als Held des Romans. Teil I und II. In: Akzente 2:125-136, 275-285.

Hofmannsthal, HugO von (1979/I): Gedichte. Dramen I. 1891-1898. In: Gesammelte Werke in zehn Einzelbänden. Bd. 1. Hrsg. von Bernd Schoeller in Beratung mit Rudolf Hirsch. Frankfurt (M.).

- (1979/II): Erzählungen. Erfundene Gespräche und Briefe. Reisen. In: Gesammelte Werke in zehn Einzelbänden. Bd. 7. Hrsg. von Bernd Schoeller in Beratung mit Rudolf Hirsch. Frankfurt (M.).

- (1979/III): Reden und Aufsätze I. 1891-1913. In: Gesammelte Werke in zehn Einzelbänden. Bd. 8. Hrsg. von Bernd Schoeller in Beratung mit Rudolf Hirsch. Frankfurt (M.).

- (1980): Reden und Aufsätze III. 1925-1929. Buch der Freunde. Aufzeichnungen 1889-1929. In: Gesammelte Werke in zehn Einzelbänden. Bd. 10. Hrsg. von Bernd 
Schoeller und Ingeborg Beyer-Ahlert (Aufzeichnungen) in Beratung mit Rudolf Hirsch. Frankfurt (M.).

KoBel, ERwin (1970): Hugo von Hofmannsthal. Berlin.

KÖNIG, CHRISTOPH (1999): Hofmannsthal als Interpret seiner selbst: Das „Ad me ipsum “. In: Euphorion 93:61-73.

Le Rider, JACQues (2001): Kein Tag ohne Schreiben. Tagebuchliteratur in der Wiener Moderne. Aus dem Französischen von Eva Werth. Wien.

Magris, Claudio / Reiniger, ANTon (1982): Jung Wien. In: Glaser, Horst Albert (ed.): Deutsche Literatur. Eine Sozialgeschichte. Bd. 8. Reinbek, 224-246.

MAYER, MATHIAS (1993): Hugo von Hofmannsthal. Stuttgart.

Müller, HARRo (1997): Zeitkonstruktionen in der Literatur der Moderne. In: MÜller, Klaus E. / RÜSEn, JÖRN (eds.): Historische Sinnbildung. Problemstellungen, Zeitkonzepte, Wahrnehmungshorizonte, Darstellungsstrategien. Reinbek, 552-567.

NIETZSCHE, FRIEDRICH (1973): Werke in drei Bänden. Bd. II. Hrsg. von Karl Schlechta. München.

Novalis (1983): Werke in einem Band. Hrsg. von Hans-Dietrich Dahnke. Berlin/ Weimar.

Nowotny, Helga (1993): Eigenzeit. Entstehung und Strukturierung eines Zeitgefühls. Frankfurt (M.).

PAX, ElgIDIUS (1955): Epiphaneia. Ein religionsgeschichtlicher Beitrag zur biblischen Theologie. München.

- (1962): Epiphanie. In: FRIES, HEINRICH (ed.): Handbuch theologischer Grundbegriffe. Bd. 1. München, 288-293.

PоснAт, GÖTZ (1984): Erlebniszeit und bildende Kunst. In: THOMSEN / HolläNDER, 22-46.

Rey, Wilhelm H. (1968): Die Drohung der Zeit in Hofmannsthals Frühwerk. In: BAUER, Sibylle (ed.): Hugo von Hofmannsthal. Darmstadt, 165-206.

RicoeUr, PAUl (1989): Zeit und Erzählung. Bd. II: Zeit und literarische Erzählung. Hrsg. von Richard Grathoff und Bernhard Waldenfels. Aus dem Französischen von Rainer Rochlitz. München.

SCHAROLD, IRMgard (2000): Epiphanie, Tierbild, Metamorphose, Passion und Eucharistie. Zur Kodierung des ,Anderen' in den Werken von Robert Musil, Clarice Lispector und J.M. Le Clézio. Heidelberg.

SCHNEIDER, IRMELA (1984): Von der Epiphanie zur Momentaufnahme. Augenblicke in der Lyrik nach 1945. In: THOMSEN / HOLLÄNDER, 434-541.

SCHOPENHAUER, ARTUR (1947): Sämtliche Werke. Bd VI. Hrsg. von Arthur Hübscher. Wiesbaden.

SimONis, ANNETTE / SimONIS, LindA (2000): Einleitung: Moderne als ,Zeitkultur"? In: SimONIS, ANNETTE/SIMONIS, LindA (eds.): Zeitwahrnehmung und Zeitbewußtsein der Moderne. Bielefeld, 7-29. 
Strauss, Bотно (1989): Paare Passanten / Niemand anderes. Berlin.

TAYlor, Charles (1994): Quellen des Selbst. Zur Entstehung der neuzeitlichen Identität. Aus dem Englischen übersetzt von Joachim Schulte. Frankfurt (M.).

Thomsen, Christian W. / Holländer, Hans (eds.) (1984): Augenblick und Zeitpunkt. Studien zur Zeitstruktur und Zeitmetaphorik in Kunst und Wissenschaften. Darmstadt.

WellBerRy, DAVID E. (2007): Die Opfer-Vorstellung als Quelle der Faszination. Anmerkungen zum Chandos-Brief und zur frühen Poetik Hofmannsthals. In: DANGELPelloquin, Elsbeth (ed.): Hugo von Hofmannsthal. Neue Wege der Forschung. Darmstadt, 186-212.

Willemsen, Roger (1984): Das Existenzrecht der Dichtung. Zur Rekonstruktion einer systematischen Literaturtheorie im Werk Robert Musils. München.

WunBerg, GotTHART (1965): Der frühe Hofmannsthal. Schizophrenie als dichterische Struktur. Stuttgart/Berlin/Köln/Mainz.

WuthenOw, RALPH-RAINER (1990): Europäische Tagebücher. Eigenart. Formen. Entwicklung. Darmstadt.

ZAISER, RAINER (1995): Die Epiphanie in der französischen Literatur. Zur Entmystifizierung eines religiösen Erlebnismusters. Tübingen.

ZIOLKOWSKI, THEODORE (1961): James Joyces Epiphanie und die Überwindung der empirischen Welt in der modernen deutschen Prosa. In: DVJS 35/4:594-616. 